\title{
On energy requirements and potential energy savings in Italian hospital buildings
}

\author{
G. Bizzarri \\ Dipartimento di Architettura, Università di Ferrara, Italy
}

\begin{abstract}
Most Italian hospitals show a significant rise in their electricity demand during the summer. Such a growth represents a high penalizing aspect especially in structures characterized by considerable needs, as the contracts with the electricity provider is normally set to the peak of consumption. An energy policy that would seek a requirement optimization through a cut of the summer peak of the electricity demand could therefore result in both energy and economic savings. In this paper the electricity needs of twenty-three hospitals located in Emilia-Romagna, north Italy, are investigated. These electricity requirements have been broken down into main end-uses confirming that compression chillers, supporting the HVAC systems during the hot season, represent the major electricity end-use and are essentially to be considered as responsible for the summer peak in electricity demand. The existence of a correlation between electricity requirements and cooling needs has been detected. Finally, a brief survey has been carried out to establish which technologies would best fit with the hospitals' needs with the aim of a rationalization of the energy demand. Among the different scenarios, solar technologies (e.g. solar collectors) in particular well suit hospital facilities since these systems achieve their peak of production in correspondence of the peak of demand during the hottest sunny days of the summer.
\end{abstract}

Keywords: hospitals energetics, electricity requirement, energy retrofit, peak-cut.

\section{Introduction}

In every temperate area, such as Italy, the cooling operations of HVAC systems are mainly concentrated during the hot summer months, from June to September. 
In this period, significant increases in the electricity requirements are frequently observed, especially in all those structures characterized by considerable energy requirements. This peak of consumption implies a significant expense, as the contracts between the users and the electricity producers are normally negotiated both on real consumption and on peak demand. A policy that lowered the electricity requirement or, at least, that rationalized demand through a peak cut, could therefore achieve a considerable financial saving. This appears to be particularly desirable for all those users, such as hospitals, that need a guaranteed grid connection calibrated on the peak of the demand. The comprehension of the electricity use characteristics is a very important issue for the Government and the administration in developing their future energy conservation plans. Besides, it has to be considered as the basic step in order to assess the impact of different retrofit strategies on energy savings and pollutant emissions reduction.

In recent years, studies on electricity demand patterns have been carried out by many researchers for different categories of users all over the world. In this research, electricity consumption has been broken down by major electricity end users such as offices [1,2], residential buildings [3-6], hotels [7], shopping malls, supermarkets [8-11] and schools $[12,13]$. It is clear evidence that, when buildings are supplied with air conditioning systems, they are expected to be the major end user in terms of electricity consumption. Some realistic correlations $[10,11,14]$ have been found between air conditioning and the related electrical energy consumption. Nevertheless, as the HVAC systems usage patterns are weather influenced, every formula has to be considered reliable only if referred to the local scenario. Studies on electricity use characteristics in hospitals received less attention in the past [15-19] even though this topic should be of particular interest since a considerable amount of the hospitals electricity consumption is due to the need for their buildings to be largely air-conditioned.

In this paper, the electricity needs of twenty-three hospitals located in EmiliaRomagna, Italy are investigated. After a four-year survey, the study confirmed that the majority of the hospitals showed a considerable increase in the electricity consumption during the hot season, together with the air conditioning operation.

In order to compare the electricity consumption pattern in the twenty-three structures, monthly consumption data were normalized following a purposelydeveloped procedure $[18,19]$. The evolution of the normalized monthly electricity requirements throughout the year clearly revealed the existence of three common patterns. These different "energy behaviours" were identified in reference to the magnitude of the summer peak of the demand. This suggested that the summer growth had to be related to both the size of the structures and the type of services provided in the hospitals. The total electricity consumption has been broken down into major end uses: heating stations, cooling stations, ventilation units, lighting, and miscellaneous electrical appliances (lifts, medical equipments, etc.). Even though some difficulties were encountered during the survey, this analysis has finally confirmed that the considerable summer increase in the electricity needs has to be indisputably correlated to operations of compression chillers providing cool air to the conditioning systems. 


\section{The survey arrangements}

At first, the electricity consumption data of twenty-three hospitals, during a fouryear period, was gathered from the electricity company. From the beginning, the collected data was seen to be non-homogeneous: the electric meter readings were not simultaneously scheduled in the various hospitals; besides, the time elapsed between two successive readings ranged randomly around a thirty day period. This fact, as well as the considerable difference in sizes of the hospitals investigated, suggested the need to define a procedure in order to compare the electricity consumption of such a heterogeneous sample [18].

The first step consisted of the computation of the daily electricity consumptions characterizing each reading period. As soon as these values were calculated, it was clear that the same data needed to be further processed by introducing a parameter that could account for the hospitals' size. In the literature it is a common practice to define this normalized parameter by dividing the consumption data by the gross floor area of the corresponding hospital. In this case, however, this modus operandi appeared not to be consistent with the cases of study, as many of the hospitals' departments were unused or under restoration at the time of the survey. The daily electricity consumptions have been then divided by the corresponding January value (with reference to both hospital and year). Such a choice has been subsequently validated by observing the occurrence of a base load: an almost weather independent energy use that remains constant throughout the year, being essentially linked to the hospital activities. This January value is characteristic especially of cold months when cooling systems do not operate. Finally, these normalized consumption data have been averaged over the four-year period providing a normalized electricity consumption parameter (NEP) defined as the averaged normalized electricity consumption characterizing the typical day, from January to December, in each single hospital. In Table 1 the twenty-three hospital NEPs are summarized.

Table 1: $\quad$ NEPs for the hospitals in the sample.

\begin{tabular}{|c|c|c|c|c|c|c|c|c|c|c|c|c|c|c|c|c|c|c|c|c|c|c|c|}
\hline Month & 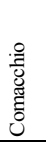 & 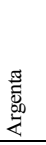 & 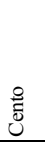 & 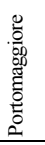 & $\begin{array}{l}8 \\
8 \\
.00 \\
0 \\
0 \\
0\end{array}$ & 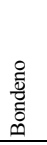 & 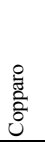 & 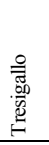 & 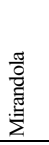 & 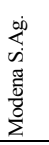 & ڤ્ & $\begin{array}{l}\frac{\pi}{0} \\
\frac{0}{0} \\
\stackrel{5}{>}\end{array}$ & 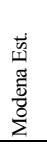 & 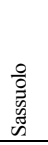 & 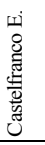 & 悹 & 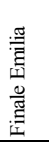 & 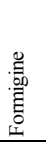 & 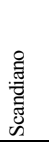 & 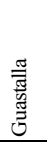 & 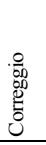 & 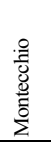 & 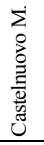 \\
\hline Jan & 1.00 & 1.00 & 1.00 & 1.00 & 1.00 & 1.00 & 1.00 & 1.00 & 1.00 & 1.00 & 1.00 & 1.00 & 1.00 & 1.00 & 1.00 & 1.00 & 1.00 & 1.00 & 1.00 & 1.00 & 1.00 & 1.00 & 1.00 \\
\hline Feb & 0.90 & 0.91 & 0.92 & 0.90 & 0.91 & 0.93 & 1.02 & 0.88 & 0.90 & 0.87 & 0.91 & 0.87 & 1.01 & 0.91 & 0.94 & 0.87 & 0.93 & 0.91 & 0.83 & 0.89 & 0.91 & 0.94 & 0.96 \\
\hline Mar & 0.99 & 0.96 & 0.98 & 0.94 & 0.90 & 0.93 & 1.04 & 0.93 & 0.95 & 1.00 & 0.98 & 0.97 & 1.05 & 0.95 & 1.01 & 0.96 & 0.99 & 0.97 & 0.88 & 0.95 & 0.96 & 0.98 & 1.04 \\
\hline Apr & 1.01 & 0.96 & 1.05 & 0.86 & 0.76 & 0.79 & 0.92 & 0.87 & 0.91 & 1.05 & 0.93 & 0.87 & 1.01 & 0.96 & 0.91 & 0.90 & 0.94 & 0.97 & 0.97 & 0.89 & 0.91 & 0.91 & 0.89 \\
\hline May & 1.11 & 1.09 & 1.18 & 0.88 & 0.82 & 0.85 & 0.93 & 0.85 & 1.13 & 1.23 & 0.93 & 1.00 & 1.09 & 1.00 & 0.96 & 0.94 & 1.32 & 0.83 & 0.89 & 1.13 & 0.95 & 0.99 & 0.89 \\
\hline Jun & 1.59 & 1.45 & 1.53 & 0.99 & 1.01 & 0.95 & 0.95 & 0.91 & 1.36 & 1.38 & 0.94 & 1.12 & 1.27 & 1.11 & 1.25 & 1.07 & 1.55 & 0.78 & 1.13 & 1.25 & 1.04 & 0.98 & 0.89 \\
\hline Jul & 1.76 & 1.46 & 1.81 & 1.09 & 1.22 & 1.07 & 1.08 & 1.06 & 1.55 & 1.46 & 0.98 & 1.24 & 1.37 & 1.30 & 1.42 & 1.28 & 1.59 & 0.74 & 1.42 & 1.47 & 1.18 & 1.16 & 1.02 \\
\hline Aug & 1.69 & 1.56 & 1.79 & 1.13 & 1.19 & 1.03 & 1.16 & 1.10 & 1.55 & 1.50 & 0.98 & 1.23 & 1.35 & 1.32 & 1.44 & 1.31 & 1.51 & 0.66 & 1.38 & 1.44 & 1.15 & 1.11 & 1.04 \\
\hline Sep & 1.50 & 1.33 & 1.35 & 0.99 & 1.05 & 0.87 & 1.15 & 0.98 & 1.25 & 1.23 & 0.93 & 0.97 & 1.10 & 1.11 & 1.18 & 1.15 & 1.32 & 0.62 & 1.17 & 1.21 & 0.99 & 0.79 & 0.95 \\
\hline Oct & 1.11 & 1.22 & 1.11 & 0.93 & 0.83 & 0.80 & 0.97 & 0.97 & 1.09 & 1.13 & 0.99 & 0.95 & 1.14 & 1.10 & 1.14 & 1.07 & 1.08 & 0.77 & 0.91 & 0.93 & 1.01 & 0.99 & 1.02 \\
\hline Nov & 1.04 & 1.10 & 1.07 & 0.90 & 0.98 & 0.87 & 1.12 & 0.95 & 1.02 & 1.00 & 0.98 & 0.94 & 1.22 & 1.08 & 1.03 & 1.04 & 0.95 & 0.85 & 0.96 & 1.02 & 1.01 & 0.99 & 1.05 \\
\hline Dec & 1.08 & 1.10 & 1.11 & 1.00 & 1.00 & 0.91 & 1.21 & 1.05 & 1.05 & 0.95 & 1.02 & 0.95 & 1.42 & 1.02 & 1.06 & 1.10 & 0.96 & 0.86 & 1.03 & 1.14 & 1.03 & 0.92 & 1.19 \\
\hline
\end{tabular}




\section{Definition of electricity consumption patterns}

By comparing the hospitals NEPs (Table 1) it is possible to outline three major trends. This differentiation in NEPs patterns is mainly due to the differences in the operations of appliances, of human activities in the hospitals, and, to a lesser extent, to the structure's size.

The first group NEPs (Fig. 1) are characterized by a significant growth during the hot months, from June to September, while they slightly fluctuate around a constant base value during the cold- and the mid-season. It can be expected (and it will be clearly demonstrated in the next paragraph, where the breakdown of electricity end users will be discussed) that this base load is mainly related to non-weather sensitive end uses (i.e. lighting, medical appliances, elevators), while the summer peak has to be considered as strongly influenced by the intensive use of air-conditioners during the hot period of the year.

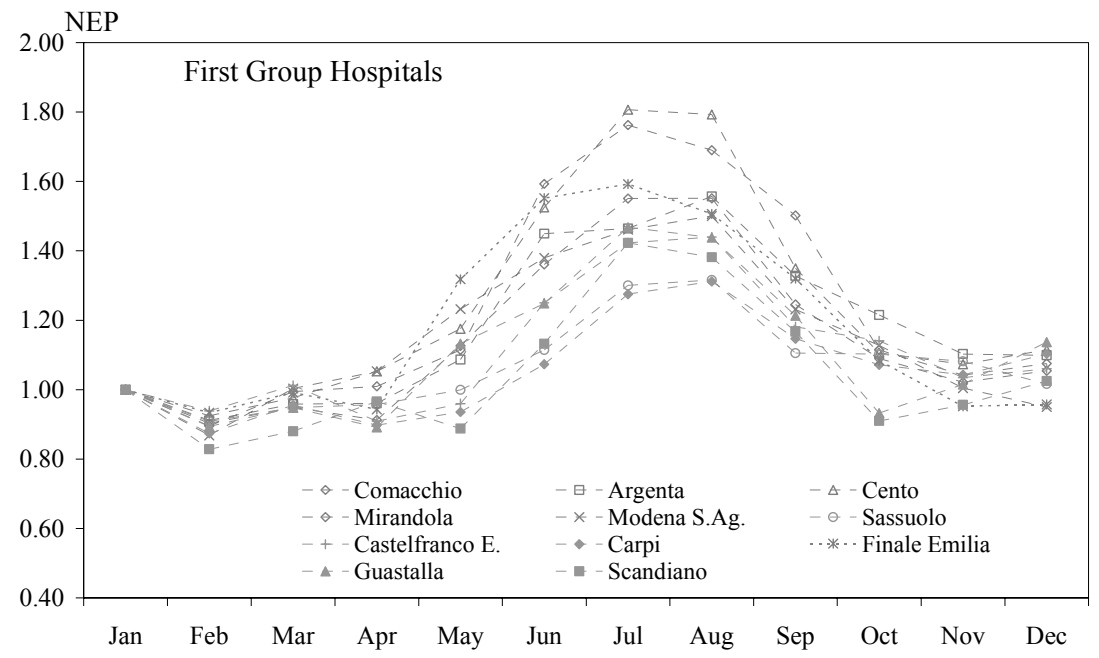

Figure 1: $\quad$ First group NEPs.

Many important hospitals in the sample (i.e. Mirandola, Modena, Guastalla, Cento, Sassuolo, Scandiano, Argenta) are included in this group. The most of these structures are characterized by electricity consumptions usually higher than $100000 \mathrm{kWh}$ per month. In fact, these hospitals, spread over the territory, must provide basic medical and/or emergency services. It implies that they are normally provided by surgery departments and are largely air-conditioned. Besides, Italian law binds to supply each operating theatre with a mandatory minimum air-exchange of 15 volumes per hour.

The hospitals grouped in the second category (Fig. 2) show smaller electricity consumptions (seldom higher than $100000 \mathrm{kWh}$ per month). In this group the NEPs between June and September do not show a very significant growth with respect to the other months in the year, sometimes they can be considered almost 
constant. In few cases they show a slight rise (always lower than 25\%) with reference to the January values. These structures normally offer limited emergency services preferring to privilege in-patient department activities and out-patient care facilities.

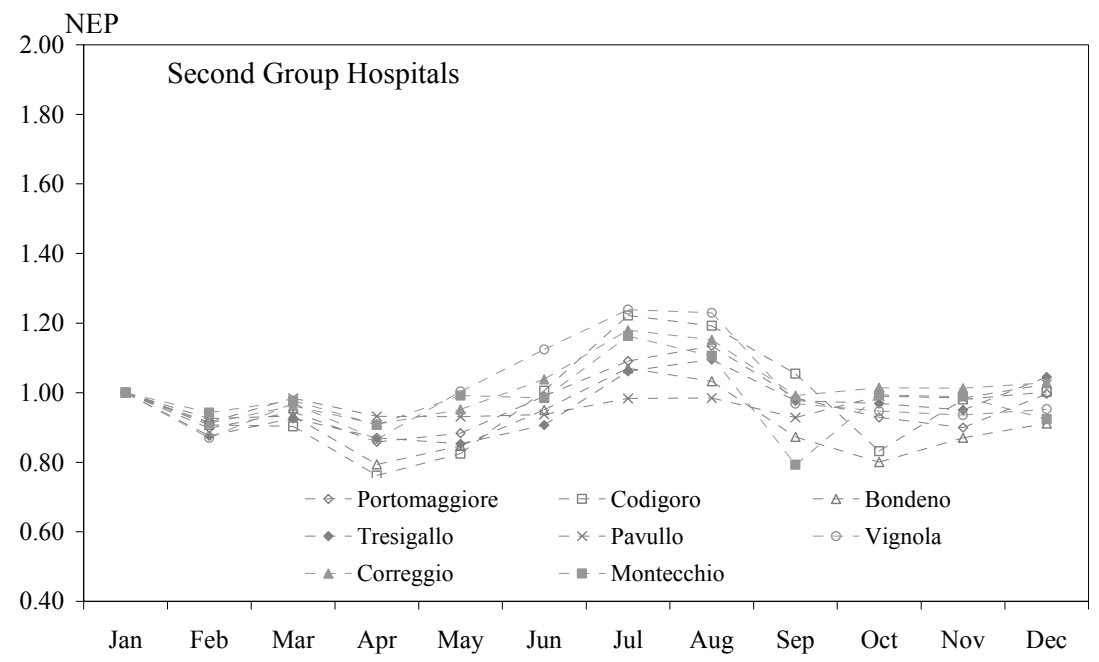

Figure 2: $\quad$ Second group NEPs.

Finally, a few structures cannot be ascribed to any of the former categories. In fact there is no clear pattern indicating any specific NEPs variation during summer. The random fluctuations characterizing the third group NEPs might be attributed to temporary closings of some departments due to frequent restoration works.

\section{Breakdown of major electricity end uses}

At this time, a study was made in order to breakdown the total electricity use into major end uses. The main difficulty in this analysis was the lack of energy submeters that could monitor the consumptions of the various appliances. An alternative approach was hence adopted. The first step was to establish a list of the typical appliances and systems that normally operate in a hospital. Then a survey was conducted to obtain data about the usage pattern of all those appliances: a fundamental issue was to recognize which end uses were weather dependent (showing seasonal variations) and/or occupancy related (showing different behaviours during the typical working day or between working days and the week end). Then, all these end uses were grouped into five homogeneous categories in relation to the service they to provide: heating stations, cooling stations, ventilation units, lighting and miscellaneous electrical appliances (i.e. lifts, medical equipments, electric heaters, air-cooled chillers, etc.). 
Heating stations In the heating station, gas-fired boilers provide the required hot water for heating and sanitary use. The hot water is delivered by electric pumps, first to heating substations, then, through dedicated lines, to localized heat exchangers (i.e. radiators, fan coils, heating batteries of the ventilation units). In the heating station, the electricity consumption is mainly due to the inlet pumps operation and, to a lesser extent, to the fans expelling the exhaust combustion fumes. The summer reduction of the heating demand does not affect the electricity consumption significantly. In fact, although these systems are used more intensively in winter, even during summer the most of them still work delivering hot water both to the sanitary utilities and to the postheating batteries of the ventilation units. To a good approximation, the electricity consumption of the heating station can be considered steady throughout the whole year.

Cooling stations The refrigeration systems installed in hospitals are normally connected to a centralized station. Those units are generally provided with compression chillers. Among the cooling station appliances, the compression chillers are the most intensive electricity consumers. These chillers mainly operate during the hot season to produce the chilled water used to feed the fan coils and the cooling batteries of the ventilation units. Other devices, such as pumps, circulating the chilled water, contribute to the total electricity consumption that can be associated to cooling station appliances. As a consequence of the North Italian climate (cold winters and hot summers), the necessity to simultaneously provide both hot and chilled water is very limited. Therefore, in many departments, the same pipes are used for cooling in summer and heating during the cold and mid seasons. This fact implies the same electric pumps, described in the heating station, are required to operate constantly, and their pattern of use remains steady throughout the year.

Hence, the only appliances in heating/cooling stations whose electricity consumption is significantly weather-affected are the compression chillers.

Ventilation units In hospitals, the operation of these units is always intensive. If, during the winter months, ventilation units normally integrate with other hot-water heating systems, such as radiators and fan coils, in summer they often constitute the only systems available for cooling the indoor space. In addition, many departments (i.e. surgery, operating theatres, intensive care unit) are required by Italian law to be constantly air-conditioned. The electricity consumption of the ventilation units is mainly related to the fans. During the survey it has been observed that the most of the ventilation units are kept at a steady load all the time they operate. Besides, the same systems are used to provide heated-air in winter and cooled-air in summer. The amount of the fans electricity consumption can then be assumed constant throughout the year.

Lighting Lighting accounts for a significant contribution to the annual electricity consumptions. Even if the hours of natural daylight varies significantly from winter to summer [18], the pattern of use of the lighting appliances remain rather steady throughout the whole year. In fact, in the hospitals, many indoor spaces have to be continuously lit for the particular needs of the healthcare facilities (i.e. operating-theatres), or for safety (i.e. interior 
areas). The amount of this "mandatory" consumption is considerable enough so that the seasonal variation related to the daylight availability is not so relevant.

Other electrical appliances All the other electrical devices are directly related to the human activities that take place in the hospitals. Some of these appliances (i.e. elevators, radiology and surgery equipment) are intensive electricity-users and are considered to be the cause for the high consumption. This end-use category constitutes the main component of the base electrical load, which can be defined as the non-weather related energy use. Although some departments, such as out-patient care facilities or offices, might be closed during some hours in a the day, the hospital must nevertheless operate and provide its basic services continuously for 24 hours, all year around. This implies that the level of electricity consumption associated to these appliances, constituting the core of the base load, is always considerable both in major and smaller structures, and that this load, being merely occupancy-related, can show no more than slight fluctuations throughout the different periods of the year.

Table 2: $\quad$ Characteristics of audited electrical appliances.

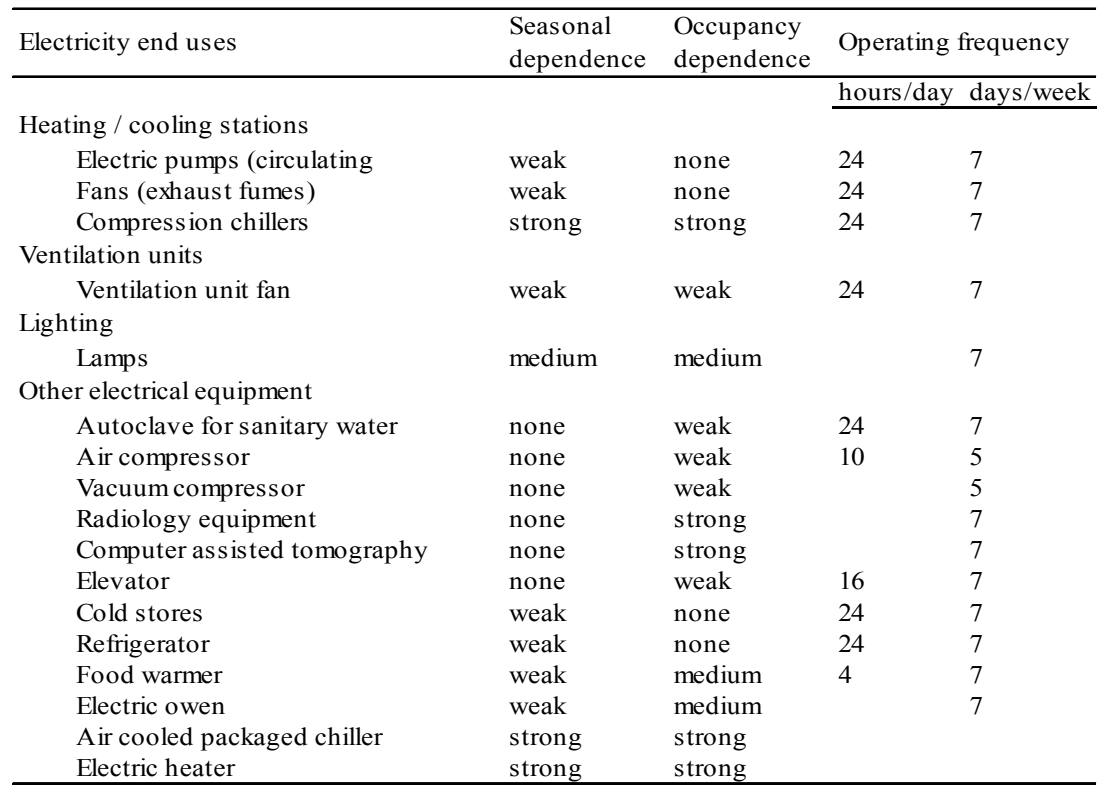

Unfortunately, a complete breakdown of the total hospital electricity-use by individual end uses was impossible. In fact, this analysis could not foresee the influence of many widespread unitary devices such as electric heaters or aircooled packaged chillers, whose operations depend on the habits and on the sensations of thermal comfort of people living in the indoor spaces. Table 2, by summarizing the information given before, simply confirms that the major weather-dependent electricity end uses are the compression chillers and, in general, all the others grid connected heating/cooling devices. Among those, 
unluckily, appliances such as electric heater or air-cooled packaged chillers can not be associated with any predictable patterns as their use is occasional and completely dependent on the habits of people working/staying in the heated/cooled indoor environment.

All the others end uses can, in general, be considered as unrelated to the weather and part of the constant base load characterizing the cold and the mid-season consumptions.

\section{Estimation of electricity consumption due to compression chillers}

In accordance with the conclusions of the previous discussion, it was clear that the summer growth of electricity consumptions had to be considered as a result of the high utilization of compression chillers supporting the HVAC systems during the hot season. Therefore the next step was to evaluate how much the cooling of indoors spaces could affect the electricity consumption.

As the compression chillers' performance is directly related to the cooling needs, a full knowledge of the summer heat transfer phenomena was required. This analysis was developed for eight hospitals in the sample. In order to evaluate the thermal requirements, since no reliable historical data were available, a digital model was created for each of the eight hospitals.

The monthly heating and cooling demands, $Q_{H}$ and $Q_{C}$, were determined using these models, first simulating the heat transfer phenomena both in transient and steady-state conditions, then processing the data obtained through properly developed spreadsheet procedures [15, 18]. The demands have been assessed assuming the restraint that the temperature and the humidity of the indoor spaces could fluctuate only within defined intervals suggested by the Italian norms. At the end of the investigation, the monthly energy requirements of the eight hospitals were completely predicted (see Fig. 3).

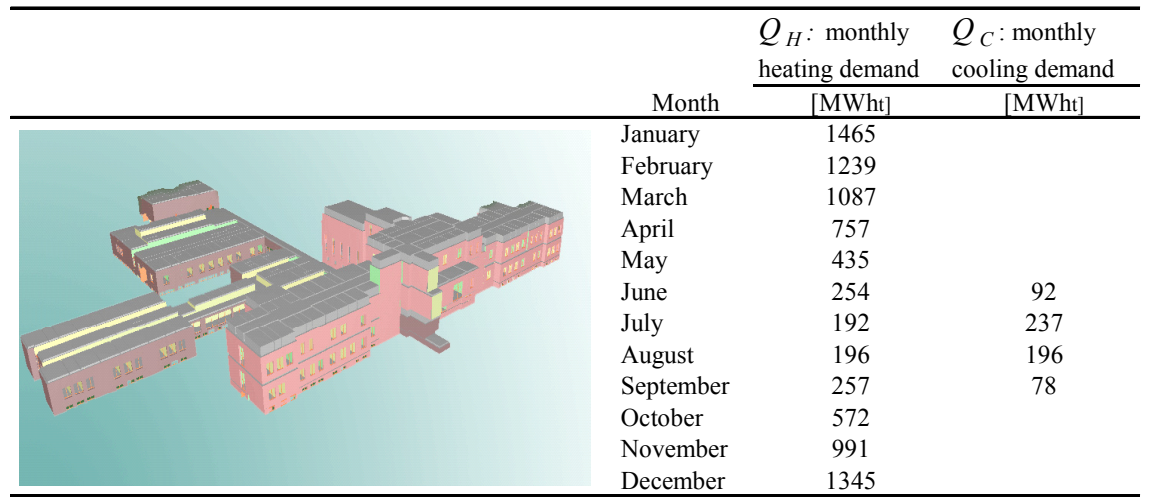

Figure 3: Predicted monthly heating and cooling demands (e.g. Argenta hospital). 
At this time it was supposed that, by exploiting the increased electricity consumption $Q_{E G, J U L}$ recorded in July (defined, for the various hospitals, as the gap existing between the July electricity demand and that averaged over the others months) to feed compression chillers, it could be possible to fulfil the whole July cooling demand $Q_{C, J U L}$. A hypothetical coefficient of performance $C O P_{C C}$, characterizing each hospital compression chiller, has then been evaluated according to the following simple energy balance:

$$
C O P_{C C}=Q_{C, J U L} / Q_{E G, J U L}
$$

Results are shown in Table 3. This table indicates realistic $C O P_{C C}$ only for Cento and Comacchio.

Table 3: $\quad$ Hypothetical compression chillers $C O P$ according to eqn (1).

\begin{tabular}{|c|c|c|c|c|c|c|c|c|c|c|}
\hline & & & 苞 & 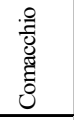 & 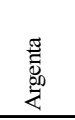 & 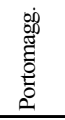 & $\begin{array}{l}8 \\
.80 \\
8 \\
\end{array}$ & 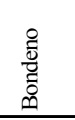 & 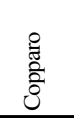 & 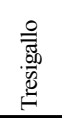 \\
\hline Cooling need in July & $Q_{C, J U L}$ & [kWht] & 258623 & 120467 & 236923 & 97552 & 56339 & 122330 & 193482 & 48257 \\
\hline Electricity gap of July & $Q_{E G, J U L}$ & [kWhe] & 91688 & 59696 & 38743 & 8318 & 8559 & 13306 & 4034 & 3778 \\
\hline Hypothetical COP & $C O P_{C C}$ & & 2.82 & 2.02 & 6.12 & 11.73 & 6.58 & 9.19 & 47.96 & 12.77 \\
\hline
\end{tabular}

The unconvincing $C O P_{C C}$ values for the others hospitals can be explained considering that the cooling needs previously determined refer to the ideal scenarios represented in the digital models, where the indoor temperatures would be completely controlled. During the survey it has been audited that, in many cases, the operating systems were not powerful enough to allow a climate control where the temperature fluctuations are greater than the values given by the norms. Data shown in Table 3 confirm that, today, in at least six of the eight surveyed hospitals, the installed chillers are not adequate to ensure occupant comfort in all the departments.

As a further stage, to a good approximation, it was assumed a given coefficient of performance equal to 3 for all the compression chillers. Such a value was also in line with those audited during the survey. In this case, again, the cooling output $Q_{C O, J U L}$ associated with the compression chillers in July, was computed assuming that the whole increase of July electricity consumption $Q_{E G, J U L}$ was entirely devoted to feed the chillers.

$$
Q_{C O, J U L}=3 Q_{E G, J U L}
$$

The comparison between the July cooling needs $Q_{C, J U L}$ (computed under the unsubstantial hypothesis of a strict indoor climate control) and the realistic outputs $Q_{C O, J U L}$ obviously show weak correlation with the exception of Cento and Comacchio (Table 4). 
The scattering between the two values is further emphasized by the effects of air-cooled screw chillers operations, whose electricity consumption could not be broken down. In confirmation of that, the structures showing the weakest correlation are also those where the largest number of independent packaged cooling systems has been surveyed.

Table 4: Comparison between cooling needs in July according to the digital models $\left(Q_{C, J U L}\right)$, and to the realistic outputs imposing $C O P=3$ $\left(Q_{C O, J U L}\right)$.

\begin{tabular}{|c|c|c|c|c|c|c|c|c|c|c|}
\hline & & & : & 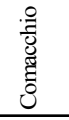 & 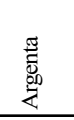 & $\begin{array}{l}\text { oj } \\
0 \\
0 \\
0 \\
0 \\
0 \\
0 \\
0\end{array}$ & $\begin{array}{l}8 \\
.80 \\
\\
\end{array}$ & 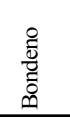 & $\begin{array}{l}\stackrel{0}{0} \\
\text { हैं }\end{array}$ & 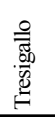 \\
\hline Cooling need in July & $Q_{C, J U L}$ & [kWht] & 258623 & 120467 & 236923 & 97552 & 56339 & 122330 & 193482 & 48257 \\
\hline Cooling output in July ${ }^{1}$ & $Q_{C O, J U L}$ & [kWhe] & 275063 & 179089 & 116230 & 24954 & 25676 & 39918 & 12102 & 11333 \\
\hline$Q_{C, J U L} / Q_{C O, J U L}$ & & $\%$ & $94 \%$ & $67 \%$ & $204 \%$ & $391 \%$ & $219 \%$ & $306 \%$ & $1599 \%$ & $426 \%$ \\
\hline
\end{tabular}

\section{Peak cut strategies}

A retrofit policy that wants to attain an effective peak cut should hence focus on the optimization of compression chillers' operation. Since the HVAC systems operating in hospitals are meant to maintain a suitable indoor environment and a mandatory high quality of services, it is not acceptable to achieve the former result by limiting their use and consequently lowering indoor comfort. Instead, an effective policy can be achieved adopting complementary systems or through energy accumulation. In this section we investigate the storage and release of cooling energy through a phase-change process [20-21]. This policy could shift most of the load coming from compression chillers from peak to off-peak time periods (i.e. during summer nights). In addition, such a policy allows exploitation of the higher $C O P \mathrm{~s}$ that can be attained at nights, when the outdoor air temperature is lower. Many other scenarios can be investigated. A wise use of absorption chillers integrating conventional compression devices could lead to significant benefits, as shown by Maidment and Tozer [9]. Moreover, solar technologies (both photovoltaic and high-temperature devices) appear to be particularly suitable for hospitals needs since the electricity peak load matches the maximum incident solar radiation. Al-Hasan et al. [22] demonstrated that a significant reduction in peak load can be achieved with grid connected PV systems. Bizzarri et al. $[15,16,18,23]$ demonstrated that the best results in terms of primary energy savings and pollutant emissions reduction are achieved when the monthly electricity self production from "not-conventional" parts of the plant (i.e. solar technologies) equals the gap existing between the average monthly electricity requirement characteristic of the summer months (from June to August) and those characteristic of the others months. Finally, it was also demonstrated that, for hospital applications, high temperature solar systems represent an effective technologies to find the peak cut thanks to the considerable 
electricity production and to the possibility of healing the thermal needs (and even feeding absorption chillers) using the abundant heat recoveries from the solar turbines [23].

\section{Conclusions}

A study of electricity consumption in twenty-three hospitals, located in EmiliaRomagna, Italy has been undertaken. Utility electricity bill records from a four-year period, supplemented by on-site operational records and survey were analyzed. An alternative systematic procedure has been developed: energy performance in every single hospital has been evaluated in terms of a parameter, called NEPs, defined as the averaged normalized electricity consumption characterizing the typical day, from January to December. The hospitals were categorized into three groups, according to the level of the summer peak use. This differentiation in NEPs patterns was to be mainly correlated to the differences in hospital appliances operations and human activities and, to a lesser extent, to the structure size.

The first group, showing a significant growth of NEPs during summer months, included the major hospitals in the sample. These structures provide many health facilities, such as interventional departments, characterized by a significant electricity use due to an intensive use of air-conditioners. The second group of NEPs fluctuated around a constant value eventually showing a limited rise during the summer months. The hospitals grouped in this category are smaller compared with first group structures and they mainly provide out-patient care facilities and in-patient facilities for older patients. These departments are normally characterized by a limited use of air-conditioning. The third group included structures that cannot be ascribed to any of the former categories.

This first analysis showed that the electricity use in the major hospitals was clearly dependent on the time of year. The monthly electricity consumption between June and September were significantly higher than those characterizing the others months. Their peak always occurred in July or August, together with the most intensive use of air-conditioners.

In order to see how significantly the common appliances normally operating in a hospital would affect its electricity consumption, a further investigation was carried out. The major electricity end uses were then grouped into five categories: heating stations, cooling stations, ventilation units, lighting and miscellaneous electrical appliances. With the exception of compression chillers, and few others grid-connected heating/cooling devices, the monthly electricity use of all other electric appliances was found to be uniform over the year.

This fact confirms that the main cause of the summer rise of the electricity requirements has to be attributed to the use of compression chillers. Therefore, an effective peak cut policy must first optimize the cool production processes.

A further investigation was then carried out in order to seek a correlation between the amount of cooling needs and the summer rise in electricity demand. An accurate energy analysis was developed for eight hospitals in the sample requiring full knowledge of the monthly cooling requirements. However, by 
making further assumptions that the compression chillers are characterized by COP factor equal to three (coherently with the values observed during the surveys), and assuming that the increase in electricity demand in summer is entirely devoted to feed the compression chillers, it has been found that the cooling production through these chillers can equal the cooling demand only in Cento and Comacchio. The inadequacy of the available data concerning the indoor spaces climate, and the impossibility of evaluating the effect of other spread cooling systems (i.e. packaged screw chillers) on the electricity demand, lead to a correlation between cool production and demand that could not yet be satisfied and suggests the need for further investigations.

Finally, a brief survey was conducted to establish which technologies would best fit with the hospitals' needs with regards to a rationalization of the energy demand. Among the different scenarios, solar technologies (i.e. solar collectors) were in particular considered well suited to hospital facilities since these systems achieve their peak of production corresponding with the peak of demand during the hottest sunny days of the summer.

\section{References}

[1] Lam, J.C., Chan, R.Y.C., Tsang, C.L., Li, D.H.W., Electricity use characteristics of purpose-built office buildings in subtropical climates, Energy Conversion and Management, 45, pp. 829-844, 2004.

[2] Suzuki, M., Oka, T., Estimation of life cycle energy consumption and $\mathrm{CO} 2$ emission of office buildings in Japan, Energy and Buildings, 2, pp. 33-41, 1998.

[3] Lam, J.C., Residential sector air conditioning loads and electricity use in Hong Kong, Energy Conversion and Management, 41, pp. 1757-1768, 2000.

[4] Tso, G.K.F., Yau, K.K.W., A study of domestic energy usage patterns in Hong Kong, Energy, 28, pp. 1671-1682, 2003.

[5] Wan, K.S.Y., Yik, F.W.Y., Building design and energy end-use characteristics of high-rise residential buildings in Hong Kong, Applied Energy, 78, pp. 19-36, 2004.

[6] Al-Ragom, Retrofitting residential buildings in hot and arid climates, Energy Conversion and Management, 44, pp. 2309-2319, 2003.

[7] Deng, S., Burnett, J., A study of energy performance of hotel buildings in Hong Kong, Energy and Buildings 31, pp. 7-12, 2000.

[8] Lam, J.C., Li, D.H.W., Electricity consumption characteristics in shopping malls in subtropical climates, Energy Conversion and Management, 44, pp. 1391-1398, 2003.

[9] Maidment, G.G., Tozer, R.M., Combined cooling heat and power in supermarkets, Applied Thermal Engineering, 22, pp. 653-665, 2002.

[10] Sezgen O., Koomey J.G., Interactions between lighting and space conditioning energy use in US commercial buildings, Energy, 25, pp. 793$805,2000$. 
[11] Zmeureanu R., Peragine C., Evaluation of interactions between lighting and HVAC systems in a large commercial building, Energy Conversion and Management, 40, pp. 1229-1236, 1999.

[12] Desideri U., Proietti S., Analysis of energy consumption in the high schools of a province in central Italy, Energy and Buildings, 34, pp. 10031016, 2002.

[13] Butala, V., Novak, P., Energy consumption and potential energy savings in old school buildings, Energy and Buildings, 29, pp. 241-246, 1999.

[14] Al-Rabghi, O.M., Al-Beirutty, M.H., Fathalah, K.A., Estimation and measurement of electric energy consumption due to air conditioning cooling load, Energy Conversion and Management, 40, pp. 1527-1542, 1999.

[15] Bizzarri, G., Morini, G.L., Greenhouse gas reduction and primary energy savings via adopting of a fuel cells hybrid plant in a hospital, Applied Thermal Engineering, 24(2-3), pp. 383-400, 2004.

[16] Bizzarri, G., Morini, G.L., Greenhouse gas reductions and primary energy savings via adoption of hybrid plants in place of conventional ones; in: Proc. of the 12th Int. Conf. on Modelling, Monitoring and Management of Air Pollution, eds. C.A. Brebbia et al., WIT Press, Southampton, pp. 32737, 2004.

[17] Williams J.M., et al., Energy consumption in large acute hospitals, Energy \& Environment, 6(2), pp. 119-134, 1995.

[18] Bizzarri, G., Analisi energetica di complessi ospedalieri, Ph.D. Thesis, Università di Ferrara, Dipartimento di Architettura, 2003. Online. www.giacomo.bizzarri.too.it $\backslash \mathrm{Ph}$.D.Thesis

[19] Bizzarri, G., Il fabbisogno energetico in ospedale. Indagine sui fabbisogni di energia elettrica in alcune strutture ospedaliere della provincia di Ferrara, Tecnica Ospedaliera, 31(8), pp. 76-82, 2001.

[20] Khudhair, A.M., Farid, M.M., A review on energy conservation in building applications with thermal storage by latent heat using phase change materials, Energy Conversion and Management, 45, pp. 263-275, 2004.

[21] Zalba, M., Marin, J.M., Cabeza, L.F., Mehling, H., Review on thermal energy storage with phase change: materials, heat transfer analysis and applications, Applied Thermal Engineering, 23, pp. 251-283, 2003.

[22] Al-Hasan, A.Y., Ghoneim, A.A., Abdullah, A.H., Optimizing electrical load pattern in Kuwait using grid connected photovoltaic systems, Energy Conversion and Management, 45, pp. 483-494, 2004.

[23] Bizzarri G., Morini, G.L., New technologies for an effective energy retrofit of hospitals, Applied Thermal Engineering, 26(2-3), pp. 161-169, 2006. 